\title{
Sobre a elaboração progressiva dos pensamentos de Husserl acerca da fantasia e da consciência de imagem através da escrita
}

\author{
Eduard Marbach \\ Institut für Philosophie, Universität Bern \\ eduard.marbach@philo.unibe.ch
}

\begin{tabular}{l} 
(c) (7) (8) S sciendo \\
Acceptance date: 18-06-2019 \\
\hline
\end{tabular}

\section{Resumo}

Este artigo é um estudo sobre a evolução do pensamento de Husserl a respeito das noções de fantasia e consciência de imagem. Mostra-se como, a partir de uma primeira fase em que ainda identificava a fantasia como uma consciência de imagem, Husserl passou gradualmente a distingui-las e a definir cada vez melhor o que é próprio de cada uma. No que diz respeito à fantasia pura, o artigo mostra como Husserl chegou à ideia de que esta é uma modificação da percepção.. No que diz respeito à consciência de imagem, apresenta-se a evolução do estatuto do objecto-imagem (que não é uma ilusão) e da natureza da referência da imagem ao tema da imagem no pensamento de Husserl. São ainda discutidos alguns exemplos que tornam problemática a referência da imagem ao seu tema, em particular o caso da representação teatral. Por fim, mostra-se como a evolução destes conceitos no pensamento de Husserl implica também uma transformação da noção de "fantasma", transformação essa que está ligada à rejeição do esquema "conteúdo da apreensão-apreensão".

Palavras-chave: Husserl, fantasia, consciência de imagem, presentificação

\footnotetext{
Abstract

This paper consists in a study of the development of Husserl's thought on the notions of phantasy and image consciousness. It shows how, following a first phase in which he still identified phantasy with image consciousness, Husserl gradually began to distinguish the two and define what is proper to each in an increasingly precise manner.

ISSN: 0874-9493 (print) / ISSN-e: 2183-0142 (online)

DOI: 10.2478 /phainomenon-2019-0002

(C) 2019 Marbach. This is an open access article licensed under the Creative Commons Attribution-NonCommercial-NoDerivs License (http://creativecommons.org/licenses/by-nc$\mathrm{nd} / 3.0 /)$.
} 
The paper then shows how Husserl came to view pure phantasy as a modification of perception. Concerning image consciousness, it shows how the status of the imageobject and the nature of its reference to the image subject evolved throughout Husserl's thought. The problems raised by this model are also discussed, in particular when it comes to cases where there is no image subject, e.g. in theatre. Finally, the paper shows how the development of these concepts in Husserl's work involves a new conception of the notion of "phantasm" - one that goes hand in hand with rejection of the 'content of apprehension-apprehension' scheme.

Keywords: Husserl, Phantasy, Image Consciousness, Representation

Estou seguro de antemão de que uma grande parte daquilo que escrevi está errado; mas estou também igualmente seguro de que se trataram de erros que, uma vez tentados, tinham de ser arriscados. Não vamos obter a verdade sólida nos fundamentos sem termos examinado

seriamente todas as possibilidades. Só examina de forma totalmente honesta uma possibilidade quem acredita nela.

Husserl a Franz Brentano, carta de Outubro de 1904

\section{A caracterização inicial da fantasia como representação de imageticidade}

Nos seus textos, Husserl aponta frequentemente para dificuldades e peculiaridades das análises descritivas, fenomenológicas da consciência. A circunstância de, através do estudo dos seus manuscritos póstumos, estenográficos, podermos presenciar os processos de pensamento e de escrita numa clareza incomparável, tanto nas clarificações conceptuais alcançadas progressivamente como nas suas falhas e aporias, é algo, por vezes, frustrante, embora seja no geral extraordinariamente fascinante do ponto de vista filosófico. Isto não se aplica apenas ao enorme número daquilo a que se convencionou chamar os seus "manuscritos de investigação". A respeito dos "problemas fundamentais de uma fenomenologia da percepção, da representação da fantasia, da recordação e do tempo", que são centrais neste artigo, Husserl diz, por exemplo, logo nas observações introdutórias à lição, dividida em quatro partes, "Elementos principais da fenomenologia e teoria do conhecimento", de 1904/05: 
Se não puder ser de outro modo, queremos pelo menos formular claramente as dificuldades e as possibilidades de compreensão; queremos sobretudo tornar claro onde residem os principais problemas, como se podem conceber de forma precisa, como se podem formular de forma definitiva. Sobre aquilo que, como autor, guardo silêncio, posso, no entanto, por isso mesmo, pronunciar-me como professor. Prefiro até falar sobre coisas que ainda não estão acabadas, mas em curso. (Husserl, 2004: 4 s.)

Isto faz pensar quase involuntariamente em Heinrich von Kleist, que começa da seguinte forma o seu pequeno escrito, «Sobre a elaboração progressiva dos pensamentos através do discurso»:

Se queres saber alguma coisa e não o consegues descobrir com meditação, aconselho-te, meu caro amigo sagaz, a falares sobre isso com o conhecido mais próximo que te apareça. Não precisa de ser uma cabeça perspicaz; também não penso que o devas interrogar: não! Em primeiro lugar, deves antes contar-lho [erzählen]. (Kleist, 1970: 319; cf. também 319-324)

Nas suas lições sobre percepção, atenção, fantasia, consciência de imagem e consciência de tempo, podemos mesmo imaginar como Husserl, por assim dizer, na verdade, contando a si mesmo, falava e com isso elaborava progressivamente pensamentos claros sobre coisas em estado fluido!

Na primeira lição de 1904/05, no seguimento da referência à clarificação analítica de Brentano das representações da fantasia em comparação com as representações da percepção, que nos meados dos anos 1880 servia de fundamento à distinção, que na sua substância se tornara muito influente para Husserl, entre representações próprias, por um lado, e impróprias ou simbólicas, por outro, este contava em retrospectiva: «as minhas próprias investigações, em que me envolvia cada vez mais, em particular depois de uma década, tinham-me conduzido por outros caminhos em pontos essenciais, e acima de tudo ensinaram-me que os problemas eram muito mais complicados e dificeis do que Brentano tinha visto» (Husserl, 2004: 4, itálicos meus). Com isto, Husserl tinha sem dúvida em mente, no que diz respeito às coisas mesmas, as suas distinções puramente descritivas no conceito do representar, desenvolvidas desde meados da década de 1890, que progressivamente o levaram da oposição clara entre representações conceptuais e intuitivas a 
distinções detalhadas no interior da classe das representações intuitivas. É sabido que Husserl tentou, nos primeiros anos, compreender a definição de Brentano de representações da fantasia, descritas como «representações não intuitivas ou impróprias, que se aproximam de representações intuitivas» (cf. Brentano, 1959: 84-86), por meio do carácter de acto específico da imageticidade e portanto distanciá-las da «autenticidade» das representações da percepção, que representam o seu objecto directamente como estando ele próprio presente nelas.

Assim, nos seus primeiros textos, Husserl empreendeu «levar a cabo tanto quanto possível o ponto de vista da imaginação e a ideia de que a representação da fantasia se pode interpretar como representação de imageticidade», mas no início da secção correspondente da lição de 1904/05 anotou à margem «embora não sem reservas» e mais tarde, talvez somente por volta de 1917, acrescentou que «posteriormente estas reservas se revelaram justificadas» (Husserl, 1980: 16). É possível que esta ideia seja sugerida em particular pelos casos de fantasias «obscuras» ou também recordações, onde o conteúdo da aparição das nossas representações parece mostrar uma semelhança mais ou menos afastada com o que é visado pela fantasia ou recordação [mit dem phantasierend oder erinnernd Gemeinten], em que portanto, de algum modo, não parece vocacionado para trazer a própria coisa à doação. De qualquer forma, em vários passos no curso das lições, Husserl conta também que, na sua apreciação das doações, é precisamente o exemplo das obscuras que o deixa hesitante (ver, por exemplo, Husserl, 1980: 87ss. e ainda 26 e 79s.). Talvez seja sobretudo essa a razão pela qual Husserl manteve ao longo de anos a sua opinião de que a sua descoberta de que, na representação de imagem, no caso de pinturas, fotografias, estátuas, etc., é dada consciencialmente [bewusstseinsmässig] uma «objectividade dupla» também é válida para as representações da fantasia e da recordação - uma objectividade dupla consistindo no objecto-imagem, que aparece na coisa-imagem física, conjuntamente com o tema da imagem apresentado no primeiro. Enquanto na percepção temos perante nós apenas um objecto apreendido, que é também visado - a paisagem que vemos, etc. - ao fantasiar teríamos dois objectos apreendidos: a imagem da fantasia e o tema da imagem que se torna manifesto através da primeira; na representação comum da fantasia, seria apenas visado o tema. 
O testar de possibilidades típico da «fenomenologia analítica» (Husserl, 1984: 17) de Husserl caracteriza em grande medida os textos póstumos. Até as oscilações na terminologia, que, tiradas do seu respectivo contexto, podem gerar confusão, estão relacionados com isso. A compreensão e apreciação das argumentações, nos textos de Husserl, apoiadas em reflexões sobre a consciência requerem um alto grau de um pensamento reconstrutivo [nachvollziehendem Denken]. Não se trata apenas de verificar concatenações lógicas entre as proposições. Para julgar da verdade do seu conteúdo tem de se exercer observação reflexiva dos objectos das análises fenomenológicas, nomeadamente dos próprios fenómenos da consciência, dos quais as afirmações pretendem tratar, comprováveis através de exemplos correspondentes. O que é característico do pensamento fenomenológico consiste neste procedimento, a realizar por cada um subjectivamente, que tem de servir de fundamento a todo o entendimento intersubjectivo acerca do valor ou ausência de valor dos resultados.

\section{A distinção entre a fantasia e a consciência de imagem a partir das lições de 1904/05}

No que se segue, de entre as possibilidades ensaiadas por Husserl de determinar a essência fenomenológica da fantasia e da consciência de imagem, gostaria de me concentrar em alguns aspectos que considero como clarificações e desenvolvimentos, reconstruíveis [nachvollziebahre] pelo pensar próprio, no curso da elaboração progressiva dos seus pensamentos sobre estes fenómenos.

Em sentido lato, Husserl compreende frequentemente a fantasia (incluindo a recordação), de um modo geral, como «a consciência caracterizada como presentificação» (Husserl, 1966: 45; cf. ainda Husserl, 1959: 113). Ele diz também: «pertence à essência da fantasia uma consciência da não-presença. Vivemos num presente, temos um campo de visão perceptivo, mas ao mesmo tempo temos aparições, inteiramente fora deste campo de visão, que representam algo não presente (Husserl, 1980: 58s.). Com referência às presentificações intuitivas, entre as quais conta também as representações da fantasia, Husserl fala também de actos sensivelmente intuitivos, referindo-se com isso a actos que trazem à aparição objectos individuais como que em si próprios ou em imagem, numa ou noutra modalidade sensível (visual, táctil, 
auditiva, etc.). Naturalmente, Husserl também reconhece o fantasiar no sentido de um representar impróprio ou simbólico, que se realiza por intermédio de conceitos ou categorialmente, ainda que de um modo não posicional ou neutral. Ele designa-o, a maior parte das vezes, como «(mero) pensar», «mero representar proposicional», também como «modificação do pensamento», de estados de coisas. Este representar conceptual-categorial, não posicional, desligado da intuitividade sensível, que embora não se encontre limitado a objectos da fantasia, que se manifestam espácio-temporalmente, pode também estar associado a eles, é tratado por Husserl de modo mais detalhado no contexto da teoria do juízo (cf. Husserl, 2009).

A concepção inicial, errónea, da fantasia e também da recordação como representação de imageticidade [Bildlichkeisvorstellung], foi corrigida de forma decisiva no decurso das lições de 1904/05, a partir do momento em que Husserl iniciou uma análise extensiva dos fenómenos de coexistência e conflito entre o campo de visão da percepção, no qual um presente se constitui, e o campo de visão da fantasia. Pois, no curso destas clarificações, Husserl pôs em evidência que, de forma radicalmente diferente da representação comum de imagem, na qual uma imagem fisicamente presente no campo de visão da percepção desempenha um papel decisivo, no decurso da fantasia [im Vollzug der Phantasie] não se constitui nenhum objecto-imagem, «que apareça no contexto do campo de visão da percepção» (Husserl, 1980: 72). Husserl chegou assim à seguinte caracterização da diferença da apreensão da fantasia relativamente à representação comum de imagem:

$\mathrm{Na}(\ldots)$ apreensão comum de imagem, algo que aparece no modo da percepção, portanto algo presente fenomenalmente, serve (...) de representante [Repräsentant] de outra coisa. Na fantasia não temos nenhuma "coisa presente" e nesse sentido nenhum objecto-imagem. (...) A relação com o presente está totalmente ausente da aparição. (Husserl, 1980: 79, itálicos meus)

No curso da sua investigação sobre fantasia e consciência de imagem na terceira parte das lições de 1904/05, Husserl foi chegando, de forma progressivamente clara, à seguinte conclusão: 
Se a nossa fantasia se ocupa, brincando, com anjos e demónios, anões e sereias ou se a nossa recordação nos transporta para o passado, que transita em configurações intuitivas perante o nosso espírito, as objectividades que aparecem não são tomadas como objectos-imagem, como meros representantes, analoga, imagens de outros: enquanto nas imagens genuínas um olhar para além, um ser remetido para outra coisa é possível e tem lugar, aqui, vendo bem, isso não tem sentido. A palavra "imaginação", o facto de se falar de imagens da fantasia e semelhantes deve tão-pouco iludir-nos aqui quanto na percepção falar-se de "imagens da percepção". Estas maneiras de falar têm origem na reflexão, que contrapõe os fenómenos da fantasia a percepções possíveis da mesma objectividade, e novamente as percepções a "coisas em si", que não podem ser dadas perceptivamente. (Husserl, 1980: 85 , itálicos meus)

Segundo o modo como compreendo as «coisas mesmas», isto é, os fenómenos da fantasia (incluindo a recordação) e da consciência de imagem, as conclusões obtidas cerca de 1904/05 apresentam três pontos particularmente problemáticos relativamente ao futuro desenvolvimento das análises descritivas husserlianas das formas de presentificação intuitiva. Por um lado, a distinção analítica da consciência alcançada entre duas formas de representação, por contraposição ao paralelismo inicial de ambas sob o ponto de vista da imaginação (ver acima), representa um ganho duradouro na compreensão de relações fenomenológicas. Por outro lado, esta distinção aplica-se:

$1^{\mathrm{o}}$, tão-pouco à determinação da representação da fantasia em si mesma quanto,

$2^{\mathrm{o}}$, à determinação da representação de imagem e,

$3^{\text {o }}$, à determinação das sensações e fantasmas como conteúdos das apreensões da percepção, por um lado, ou da fantasia e recordação, por outro.

Agora gostaria de examinar um pouco melhor estes três domínios de problemas. 


\section{Da fantasia como consciência pura de presentificação à fantasia como modificação da percepção}

Sobre o primeiro ponto, na lição de 1904/05, depois do destaque dado à consciência de imagem, Husserl constata com respeito à fantasia: «a aparição da fantasia, a simples, (...) refere-se ao objecto de uma forma tão unímoda quanto a percepção» (p. 85). E, em particular, logo em seguida, referindo-se às fantasias, ou também recordações, claras, totalmente adequadas, por oposição às obscuras ou mesmo totalmente obscurecidas, acrescenta:

Pode dizer-se das fantasias claras que se opera nelas uma consciência pura de presentificação com base em fantasmas e na apreensão objectivante. Quando os fantasmas são objectivados, não se constitui previamente um objecto-imagem (Bildobjekt) a pairar e a aparecer como presente, antes o que aparece é imediatamente o que não está presente. (...) em si mesma a representação da fantasia não contém nenhuma intenção multímoda, a presentificação é um modo último de representação intuitiva, exactamente como a representação da percepção, como a presentação ${ }^{1}$ [Gegenwärtigung] (Husserl, 1980: 85s., itálicos parcialmente meus)

No entanto, anos mais tarde é esta conclusão que Husserl virá precisamente a pôr em causa e - com base numa análise mais aprofundada dos fenómenos e levando em conta a consciência interna ou consciência do tempo - explicar de outro modo a estrutura intencional da fantasia como consciência de presentificação, por meio do conceito de modificação reprodutiva das vivências. Esta nova análise vem ao de cima de forma clara nos manuscritos de

\footnotetext{
${ }^{1}$ N.d.T.: «Presentação» traduz o alemão «Gegenwärtigung». A tradução mais natural talvez fosse «apresentação», mas como esta última solução já foi usada para «Darstellung», preferiu-se recorrer a um neologismo. De todo modo, este neologismo pode-se justificar por várias razões. Em primeiro lugar, ele já foi estebelecido em outras traduções portuguesas de Husserl (ver a tradução portuguesa das Lições sobre a consciência interna do tempo). Em segundo lugar, a palavra Gegenwärtigung também não existe no léxico alemão, tendo sido criada por Husserl a partir do adjectivo gegenwärtig (o adjectivo português «presente»). Por último, uma vez que gegenwärtig e Gegenwärtigung contêm na sua raiz a referência a Gegenwart (o substantivo português «presente»), faz sentido usar «presentação» por manter precisamente essa mesma remissão para a palavra «presente».
} 
investigação do ano de $1912^{2}$. Husserl escreve por exemplo: «Temos de dizer o seguinte: toda e qualquer vivência admite uma modificação fundamental. Ela chama-se modificação reprodutiva, e a vivência não modificada chama-se, em relação à primeira, impressiva» (Husserl, 1980: 330).

Numa anotação à margem, Husserl precisa que:

Em relação a toda e qualquer vivência, a consciência interna é impressão: toda e qualquer consciência interna é impressivamente consciente. Toda e qualquer modificação reprodutiva é uma reprodução de uma vivência interna "de que temos impressivamente consciência", a consciência da própria reprodução é impressiva [die Reproduktion selbst ist impressiv bewusst]. (Husserl, 1980: 330, nota 3)

Esta nova descrição assenta nas análises da consciência interna do tempo, com as quais Husserl se começara a ocupar na quarta parte das lições de 1904-05, «Fenomenologia do tempo». No manuscrito original, no início desta última parte da lição, escreve já:

É manifesto que existe uma conexão íntima entre os actos intuitivos e a consciência do tempo, que uma análise da consciência perceptiva, da consciência de fantasia, de recordação e de expectativa não está acabada enquanto a temporalidade não for incluída na análise e que inversamente uma análise da consciência do tempo pressupõe, em grande medida, a análise daqueles actos. (Husserl, 1966: 394)

Ainda que não logo no início, mas progressivamente, nos anos que se seguiram às lições, Husserl alcançou uma compreensão cada vez mais detalhada da «intencionalidade extremamente peculiar das 'modificações'» na «Clarificação de diversos tipos fundamentais de modificação e de 'presentificação'» ${ }^{3}$. A

\footnotetext{
${ }^{2}$ Hua XXIII, $\mathrm{n}^{\circ}$ 15, Modi der Reproduktion und Phantasie, Bildbewusstsein (auch in Beziehung auf die Stellungnahmen (Husserl, 1980: 329ss.) e $\mathrm{n}^{\circ}$ 16, Reproduktion und Bildbewusstsein. < .. > (Husserl, 1980: 464ss.).

${ }^{3}$ Cf. Manuscrito L I 19, p. 9b, aproximadamente de 1918, citado integralmente na minha introdução à Husserliana XXIII (Husserl, 1980: LXIII e LXX). - Entretanto também publicado como texto $\mathrm{n}^{\circ} 9$ de Die Bernauer Manuskripte über das Zeitbewusstsein (1917/18) (Husserl, 2001: 175s).
} 
conclusão principal é claramente contraditória com a descoberta de 1904/05, onde ainda se dizia que a fantasia ou alguma forma de presentificação pura intuitiva não continha «em si mesma» «nenhuma intenção multímoda» (ver acima). Em contraposição, Husserl mais tarde pôde precisar de forma plena a descrição da modificação de presentificação, que começara por compreender como «um acontecimento da consciência interna» (Husserl, 1966: 368) ou da consciência do tempo, deste modo:

(...) toda e qualquer "modificação" (é) caracterizada pelo facto de estar compreendida [beschlossen] nela própria a relação com outra consciência, da qual ela se diz modificação, uma consciência, que não está verdadeiramente contida [enthalten] nela e que contudo é apreensível por uma reflexão direcionada de forma apropriada. (...) Correlacionadas com isso estão ainda as reflexões específicas referentes aos correlatos de actos respectivos. (Manuscrito L I 19, p. 10a; ver nota 11)

O que Husserl acentua a partir daí nos tipos principais de actos presentificantes é a sua «maravilhosa intencionalidade entrelaçada [ineinandergeflochtene]» (Husserl, 1959: 128; itálicos parcialmente meus). À luz do exemplo da recordação, que está incluída no seu conceito lato de fantasia como presentificação, esta descoberta específica da análise fenomenológica reflexiva é descrita num texto aproximadamente de 1911 ou início de 1912, numa notável dupla versão, do modo que se segue; uma vez assim:

A recordação é uma modificação reprodutiva da percepção, ela tem a notável particularidade de ser também presentificação da percepção e não apenas presentificação do percepcionado. Eu recordo-me do almoço. Nisto "encontra-se" também a recordação da percepção do almoço (uma vez que abstraiamos da direcção do visar).

Por outro lado, um pouco mais à frente no mesmo texto, Husserl resume deste modo a descoberta:

A percepção externa é percepção. E se a modificação da percepção é agora uma recordação correspondente, temos aqui a peculiaridade de que a 
recordação correspondente não é apenas recordação da percepção, mas que a modificação da percepção é também recordação do percepcionado. ${ }^{4}$

Husserl salienta de forma clara em numerosos textos a duplicidade, contida na essência da reprodução como reprodução da impressão, da própria consciência presentificante, isto é, a duplicidade da sua relação com o objecto (Husserl, 1980: p. 330s. e passim). Para além disso, reconhece que, entre os «modos de reprodução», os fenómenos de tomada de posição (Husserl, 1980: 329ss.), cognitiva, expressando-se em juízos, assim como as tomadas de posição afectivas e as avaliações estéticas, também devem ser incluídos, fenómenos que como tais têm um alcance que vai para além do domínio das presentificações intuitivas da fantasia, da consciência de imagem e da recordação e chega à região da teoria do juízo, das «suposições» e das meras modificações de «pensamento». Nestes textos, Husserl investigou os fenómenos de caracterização modal da reprodução interna (do próprio vivenciar) e da caracterização a partir da conexão posterior do vivenciar, a possibilidade de ocorrência e desaparecimento de tomadas de posição e também de actos emotivos (Husserl, 1980: 335ss., 373ss., 464ss.), que se podem referir às próprias vivências ou aos seus objectos intencionais (Husserl, 1980: $337 \mathrm{e}$ passim, pp. 464ss.). Para além disso, discutiu, à luz do exemplo do fantasiar, os fenómenos do operar [des Vollziehens] nas reproduções (do vivenciá-las, do estar atento [Husserl, 1980: 339 ss.]). Analisou também os fenómenos complexos de adequação ou falta de adequação dos actos judicativos e espirituais às fantasias que lhes servem de base (incluindo a recordação) (Husserl, 1980: 373ss.) e discutiu-os à luz do exemplo da leitura e criação de uma fábula (Husserl, 1980: 379ss.). Todas estas investigações mostram à saciedade que, mais tarde, Husserl, pouco tempo antes das Ideias I (1913), deixou de compreender a relação intencional das vivências de presentificação pura como uma estrutura «simples», «unímoda», tal como esta ainda lhe parecera cerca de 1904/05.

\footnotetext{
${ }^{4} C f$. o texto $\mathrm{n}^{\circ} 14$ de Hua XXIII (Husser, 1980: 305s. e 308; itálicos meus, para salientar a dupla direcção da descrição, dirigada (a) ao objecto presentificado (por exemplo, o almoço) ou alternativamente (b) à percepção presentificada, modificada reprodutivamente, implicada intencionalmente (aí "contida"), ou seja, à vivência.
} 


\section{O estatuto do objecto-imagem e a dupla apreensão objectivante da consciência de imagem}

Sobre o segundo ponto, em comparação com textos posteriores, salta à vista que, nas lições de 1904/05, na tentativa de levar a cabo o ponto de vista de que a representação da fantasia se pode interpretar como representação de imageticidade, Husserl dá repetidamente expressão a duas ideias. Por um lado, que a representação da fantasia apresenta «ainda sérias dificuldades e obscuridades»; que a sua "consideração sob o título geral de imaginação» deixa-o com «o sentimento de uma certa insatisfação», porque «a situação (...) da representação da fantasia não é certamente a mesma da representação física de imagem». Por outro lado, que no curso da «distinção entre representação da fantasia e representação comum de imagem», finalmente bem-sucedida, acredita poder observar com segurança que: «a representação de imagem tornou-se completamente clara para nós» (Husserl, 1980: 54, itálicos meus). Husserl observa novamente

Uma coisa à partida é clara: a "imagem", no caso físico, nomeadamente o objecto-imagem é um fictum, um objecto da percepção, porém um objecto aparente. Aparece do mesmo modo que uma coisa física real, mas em conflito com o presente actual que se produz numa percepção sem conflito. Este fictum, ou antes a consciência do fictum, interpenetra-se com a consciência da representação [Repräsentation]. Deste modo, desponta aqui a consciência imaginativa [imaginative]. E desponta no novo conflito entre fictum e imaginatum. (Husserl, 1980: 54)

Husserl exprime-se de um modo totalmente semelhante um pouco mais tarde no curso das lições:

[na] (...) apreensão perceptivo-imaginativa $[\text { perzeptiv-imaginativen }]^{5}[\ldots]$, ou seja, na apreensão comum de imagem, algo que aparece no modo da

\footnotetext{
${ }^{5}$ N.d.T.: Para além de Wahrnehmung, que estamos a traduzir como «percepção», Husserl usa ainda Perzeption e respectivos cognatos. Uma vez que a língua portuguesa não dispõe de outra palavra, que não "percepção», para distinguir Perzeption de
} 
percepção, portanto algo presente fenomenalmente (ainda que caracterizado como objecto aparente), funciona como representante de outra coisa. De facto, exercitando a nossa consciência da imaginação imanente, vemos o que não está presente naquilo que aparece, mas o primeiro aparece no modo de algo que aparece no presente, é uma coisa que aparece perceptivamente [perzeptiv] (Husserl, 1980: 79)

No entanto, esta clareza, atingida, a julgar pelas aparências, em 1904/05, na análise da consciência comum de imagem, cujo ponto principal concerne o modo de doação do objecto-imagem, será mais tarde repetidamente problematizada por Husserl. Se, nas primeiras investigações, Husserl diz que «o objecto-imagem aparece no meio da realidade da percepção e como que reivindica possuir, no meio dela, realidade objectiva» (Husserl, 1980: 47) ou se ele descreve este modo de doação como «um objecto-imagem que aparece presentemente, (...) um objecto que se comporta como parte dos objectos do campo de visão» (Husserl, 1980: 83) ou como «um fictum, um objecto da percepção, porém um objecto aparente» (Husserl, 1980: 54), então pode parecer, pelo menos num primeiro momento, que Husserl seria da opinião de que a imageticidade se constituiria, no fundo, como uma consciência de fictum no sentido de uma ilusão; como se a imagem-fictum se revelasse, no solo da percepção, no conflito entre as posições perceptivas, como mera aparência, como «um nada» (Husserl, 1980: 46), contudo precisamente como um objecto da percepção que aparece no presente, análogo à «ilusão sensível» (Husserl, 1980: 32).

De facto, já em 1904/05 há suficientes passos em sentido contrário, onde Husserl percebe claramente que a consciência de imagem requer fundamentalmente uma consciência de presentificação, graças à qual a relação com o tema da imagem se constitui. O mero percepcionar e o conflito de posições perceptivas não chegam seguramente, segundo Husserl, para tornar compreensível a relação de presentificação: «na imagem intuímos a coisa. A consciência de imagem tem uma coloração que lhe confere uma significação que remete para lá do seu objecto primário: o carácter de representação

Wahrnehmung, indicarei através da colocação do original em parênteses rectos à frente sempre que Husserl usar Perzeption e cognatos. 
[Repräsentation] segundo a semelhança» (Husserl, 1980: 26). A apreensão não é aqui «uma mera apreensão da percepção»; é verdade que as «sensações como conteúdos da apreensão também» desempenham um papel, mas na representação imaginativa [in der imaginativen Vorstellung] tal como ela se efectua na contemplação de um quadro,

o resultado da apreensão (...) não [é] uma percepção. A madona de Rafael que vejo na fotografia não é, como é evidente, a figurinha que aparece fotograficamente. Eu não efectuo, portanto, uma mera percepção: a aparição da percepção põe em imagem um objecto não percepcionado. (Husserl, 1980: 26)

É verdade que na intuição da imagem temos apenas

uma aparição (...), a do objecto-imagem. Mas temos mais do que uma única apreensão (ou, se quiserem, mais do que uma única objectivação) através da qual este objecto-imagem se constitui para nós. Se não, não poderia ser visado mais do que este objecto. (...) É nisto que consiste o facto de, fenomenologicamente, o objecto-imagem não aparecer somente, mas comportar também um novo carácter de apreensão, que de certo modo se interpenetra e funde com o original e que não remete, por assim dizer, simplesmente para lá do conteúdo do que aparece, mas antes para o seu interior ou remete através deste conteúdo para o objecto verdadeiramente visado. O que no conteúdo do objecto-imagem desempenha a função representativa distingue-se de uma maneira particular: isso apresenta, presentifica, põe em imagem, torna intuitivo. $\mathrm{O}$ tema olha-nos como que através destes traços. (Husserl, 1980: 30)

Logo em seguida, Husserl regista a compreensão decisiva da estrutura da presentificação da consciência de imagem do modo que se segue:

Se com a imagem não é dada a relação consciente com qualquer coisa figurada, não temos imagem nenhuma. Esta relação consciente, no entanto, é dada através daquela consciência peculiar de presentificação de algo que não aparece em algo que aparece, de acordo com a qual o que aparece, em virtude de certas particularidades intuitivas, se dá como se fosse a outra coisa. (...) Como é possível semelhante coisa, uma vez que apenas a imagem, mas 
não o tema, pertence à aparição, seria um milagre ou absurdo caso as duas apreensões objectivantes não estivessem entrelaçadas uma na outra. $\mathrm{O}$ tornar intuitivo na imagem, que no aparecer da imagem tem consciência do tema da imagem, não é um carácter qualquer que adere à imagem, antes a intuição do objecto-imagem desperta precisamente uma nova consciência, uma representação de um novo objecto (...). Esta nova representação não se encontra, no entanto, ao lado da representação do objecto-imagem, mas coincide com ela, interpenetra-a e confere-lhe nesta interpenetração o carácter de objecto-imagem. (Husserl, 1980: 31; parte dos itálicos meus)

Por conseguinte, é necessário entender que, apesar de se fundar necessariamente em algo que aparece perceptivamente [perzeptiv], a consciência genuína de imagem só ocorre graças à relação presentificante com a coisa figurada. ${ }^{6}$ Neste sentido, a consciência de imagem é para Husserl fundamentalmente uma variante da presentificação intuitiva, nomeadamente da fantasia no sentido de fantasia perceptiva, mas de modo nenhum apenas uma variante do percepcionar [des Perzipierens]. No «resumo» de 7 de Fevereiro de 1905 (Husserl, 1980: 82ss.), Husserl, ele próprio, observa que o que «temporariamente o perturbou e confundiu» a respeito do «carácter de imagem na fantasia» é «a evidente afinidade entre a consciência imanente de imagem, voltada para dentro, e a consciência de fantasia»; por outras palavras, a circunstância de «no carácter comum de imagem a fantasia ser o momento essencial, tal como acabámos de reconhecer» (Husserl, 1980: 87, itálicos meus). Entretanto, depois de ter explicado a fantasia como «uma consciência pura de presentificação», que «não tem ela mesma o carácter de imagem» (Husserl, 1980: 84s.), pôde, a respeito da fantasia e da consciência de imagem, observar, por assim dizer, em sentido inverso:

\footnotetext{
${ }^{6}$ Já nas lições de 1904/05, Husserl desenvolve - algo a que aqui se faz meramente referência - diferentes modos de relação presentificante, detalhando e esclarecendo melhor, em primeiro lugar, a importante distinção entre a imageticidade, interna, imanente, e a externa, simbólica, depois também a possibilidade da transição gradual da consciência externa de imagem para a consciência de representação [Repräsentation] analógica, a genuína consciência de símbolo e finalmente a consciência de signo (Husserl, 1980: 34ss.). Sobre esta distinção, ver também o importante anexo V "Bildvorstellungen (bildliche - symbolische)", aproximadamente de 1905 (Husserl, 1980: 141ss.)
} 
De facto, a consciência é, na sua essência, a mesma em ambos os lados; nomeadamente teremos de dizer com propriedade: esta consciência imanente de imagem é consciência de fantasia, isto é, considerada em si mesma, não se distingue de modo nenhum de uma consciência de fantasia. (p. 86; itálicos parcialmente meus)

Claramente, isso não significa outra coisa senão que o «momento mais essencial» da consciência de imagem é a consciência de presentificação. No entanto, esta, como fantasia perceptiva [perzeptive], ao contrário da fantasia pura - prossegue Husserl - «interpenetra-se aqui com uma consciência presentativa [präsentativen]» (Husserl, 1980: 86) e confere, por esse meio, ao que aparece perceptivamente [perzeptiv] o «carácter de irrealidade» (Husserl, 1980: 47), isto é, «o carácter de objecto-imagem» (ver acima), todavia não o de uma coisa aparente, ilusória e nula.

Deste ponto de vista, seria já claro no tempo das lições de 1904/05 que, na consciência de aparência ou de irrealidade, no caso de uma imagem, não se trata de uma verdadeira consciência de fictum no sentido de uma ilusão. Em particular, nos textos de cerca do ano de 1912 (Husserl, 1980: 486ss.), Husserl põe em evidência esta conclusão de forma clara. «A imagem não é uma ilusão» (Husserl, 1980: 486). Aquilo que é decisivo no que agora é dado a pensar por Husserl é que: o autêntico fictum de uma ilusão aparece directamente na unidade da realidade, é uma aparição com carácter posicional que entra em conflito com outras posições, de tal modo que o fictum se revela, no conflito das posições, como ilusão, como mera aparência ( $c f$. o exemplo frequentemente usado por Husserl da boneca de cera - ser humano). Em contrapartida, na imagem, o carácter de irrealidade não é o resultado de um conflito entre diferentes tendências de crença. Ele apoia-se antes, como Husserl num outro texto de 1912 exprime de forma muito mais clara em comparação com as lições de 1904/05, no facto de que qualquer coisa que não está imediatamente presente é fantasiada no interior [hineinphantasiertes] daquilo que aparece perceptivamente: a imagem não «aparece» verdadeiramente na unidade da realidade, «mas antes num espaço próprio, que em si mesmo não tem nenhuma relação directa com o real». O fictum-imagem aparece «sem possuir o carácter de realidade, sem 'reivindicar' realidade, uma reivindicação que tivesse 
primeiro de ser aniquilada» (Husserl, 1980: 480) ${ }^{7}$. Num outro texto, pode-se ler de modo semelhante: «a imagem não tem o carácter de nulidade, a qualquer momento eu posso supô-la nula, dizer que não é nada, que é uma mera imagem» (Husserl, 1980: 487). Relativamente à apreensão de imagem, tal como Husserl descreve os fenómenos nestes textos de cerca de 1912, tudo se passa na verdade

exactamente como se eu fantasiasse de forma viva qualquer coisa no interior da realidade. A diferença reside no facto de a "imagem da fantasia" ser reprodutiva, a imagem vista, perceptiva [perzeptiv]. Ambas são imaginação. Isso nunca pode ser esquecido e é absolutamente certo. Era absolutamente correcto quando eu tentava sempre de novo tomar a apreensão de imagem como imaginação. É imaginação. A imagem torna-se nula somente através da conexão com a realidade: conforme eu a tomo neste contexto (ou como tendo um contexto, por exemplo, o tema da imagem, onde começa a moldura, em relação espacial com o espaço real, etc.), conforme eu assim a suponho, ela torna-se nula. (Husserl, 1980: 480; itálicos parcialmente meus)

A apreciação do modo de doação do objecto-imagem parece, acima de tudo, problemática, isto é, desafiante para o pensamento próprio que verifica reflexivamente ${ }^{8}$. Em alguns textos da Husserliana XXIII, não apenas nos primeiros, também por exemplo no texto $\mathrm{n}^{\mathrm{o}} 18$, aproximadamente de 1918 , e no texto $\mathrm{n}^{\mathrm{o}} 20$ da primeira metade da década de 1920 (por exemplo, Husserl, 1980: 575, 580), Husserl apresenta a situação como se o objecto-imagem fosse uma doação perceptiva [perzeptive], que se apresentaria «como realidade presente», que Husserl caracteriza, no entanto, novamente como «realidade como-se» e diz «a imagem apenas paira perceptivamente [perzeptiv]» (Husserl, 1980: 506). Em contrapartida, no texto $n^{\circ} 16$, aproximadamente da Primavera de 1912, Husserl examina seriamente outra possibilidade por caminhos algo intrincados. De início, começa: «o que distingue o caso da representação de

\footnotetext{
${ }^{7}$ Cf. Beilage L, «Zu Imagination», aproximadamente da Primavera de 1912 ou um pouco mais tarde, (Husserl, 1980: 479ss.)

${ }^{8}$ Sobre a fenomenologia da fantasia e da consciência de imagem, chegaram ao meu conhecimento ensaios muito interessantes e originais de Christian Ferencz-Flatz (2009), Ijuin Reiko (2011), Andrea Smaranda Aldea (2013), Peter Shum (2015) e Claudio Rozzoni (2016).
} 
imagem do da fantasia (reprodução) é o facto de a primeira, se nos ativermos ao objecto-imagem, ser precisamente percepção, a última, reprodução; isto significa que a última tem uma modificação própria, para além da modificação posicional [tem] a [modificação] reprodutiva, que falta à primeira e a tinge completamente» (Husserl, 1980: 466; itálicos meus). Na continuação da nota, lê-se em seguida: «o modo como agora interpretamos a consciência de imagem é decisivo. Não teremos de dizer: a apresentação pertence à essência da consciência de imagem; a consciência de imagem não é simplesmente consciência perceptiva [perzeptives Bewusstsein] e quando muito uma consciência perceptiva [ein perzeptives Bewusstsein] que ainda se encontra entretecida com uma [consciência] reprodutiva (a saber, uma consciência de fantasia). Isto não está correcto» (Husserl, 1980: 471). Em seguida, Husserl recomeça:

sem dúvida, a consciência de imagem tem em comum com a consciência perceptiva 'conteúdos sensíveis' implicados em si, que se encontram nela, que se podem extrair. Mas se considerarmos atentamente as aparições de imagem, nas quais árvores, ser humanos, etc., como seres humanos-imagem, árvoresimagem aparecem, descobrimos que, tal como na fantasia reprodutiva, as aparições não são como que meras aparições percipientes, mas antes imaginantes ... a própria aparição apresenta a aparição, a apreensão não é simplesmente apreensão, mas antes apresentação de apreensão (Husserl, 1980: 471s.).

Depois, considera novamente se não deve retirar o que acabou de dizer; Husserl pergunta se «não podemos tomar a sensação como sensação e, além disso, a apreensão como apreensão que não apresenta, efectuar uma transformação da consciência que leve a cabo a apreensão como apreensão perceptiva?» (Husserl, 1980: 472). E, de novo, de modo semelhante a alguns passos das lições de 1904/05, mas em contradição não só com a abordagem que acabou de se considerar, mas também com as reflexões citadas acima do texto $\mathrm{n}^{\circ} 17$ e do anexo L da Husserliana volume XXIII, aproximadamente da mesma época, que o texto discutido agora, cerca de 1912, Husserl prossegue: «não teremos de dizer: a apreensão perceptiva tem o carácter de um fictum, aparece perceptivamente [perzeptiv] nela um 'objecto-imagem', uma aparência, 
'suprimida' ou caracterizada como nula através do contexto perceptivo da crença?» (Husserl, 1980: 472; sobre isto $c f$. também nota 2). No entanto, Husserl vai mais longe: «mas pergunta-se agora se esta apreensão é uma vivência real ou possível; se ela é real, mas não é uma vivência 'efectuada' em sentido pleno (manifestamente a última). Não estamos voltados para o objecto aparente (objecto-imagem), todavia ele aparece» (p. 472, juntamente com as notas 3 e 4). Em contrapartida, logo em seguida aborda ainda a «outra possibilidade»: «a consciência de imagem não aparece, mas está constituída de tal modo que posso transformar a imaginação numa aparência de percepção [Schein-Perzeption], uma quase-percepção». Resultado: «estas são questões que têm consequências pesadas» (Husserl, 1980: 472 s., também p. 473, nota $1)$.

A resposta que Husserl esboça no texto $\mathrm{n}^{\circ} 16$ contém uma autocrítica explícita às suas primeiras análises, em particular às das lições de 1904/05. Husserl escreve: «as distinções estudadas por mim, que talvez não tenham sido interpretadas de forma totalmente exacta, não devem gerar confusão. Por objecto-imagem pode-se entender o objecto realmente percepcionado... por contraposição à objectividade de apresentação [Darstellungs-Objektität]. No entanto, se olharmos atentamente, encontramos diferenças entre as imagens». Em seguida, retoma um exemplo das lições de 1904/05 (Husserl, 1980: 44): «O meu exemplo da teologia de Rafael: os pequenos querubins cinzentos, as pequenas figuras femininas, a isso chamei objectos-imagem, as pequenas figurinhas. A coisa apresentada, o tema é a sublime forma feminina, etc.» (Husserl, 1980: 473). Em seguida, de modo semelhante ao caso das aparições de imagem, nas quais seres humanos, árvores «aparecem como seres humanosimagem, árvores-imagem» (ver acima), diz-se também aqui: «se no entanto observarmos melhor, a seguinte perspectiva da situação oferece-se: as pequenas figurinhas são já objectos apresentados», substituindo, algum tempo depois, «apresentados» por «meramente representados» e completando ao mesmo tempo a frase do modo que se segue: «(não são aparências [Scheine], não aparecem numa percepção posicional [setzenden Perzeption], apenas rebaixada modalmente)» (p. 473 e 73, nota 4). Substituindo o exemplo da madona de Rafael pelo de uma fotografia da sua mulher, Husserl prossegue no mesmo sentido: «contemplando o pequeníssimo busto fotográfico de Malvine, não tenho de tomar o que é aí intuído como «aparência». Aparece uma coisa muito 
pequena e em cores fotográficas, mas é já uma coisa apresentada (uma coisa meramente representada), não é percepcionada [Perzipiertes] (posta perceptivamente [perzeptional Gesetztes]), não é caracterizada como aparência» (p. 473, juntamente com as notas 5 e 6).

Todas estas precisões confluem para que Husserl, num texto de 1912, possa explicar em resumo: «1) temos de separar a apreensão do objecto-imagem da consciência de uma aparência perceptiva [perzeptiven Scheines] (um nada). A primeira não é posicional, a última é. 2) Com a apreensão do objecto-imagem, temos simultaneamente a apresentação» (Husserl, 1980: 474). No que segue, Husserl põe em evidência que a «apresentação» tem «as seguintes características em comum com a reprodução», com a presentificação (ver acima), «a saber que em toda a componente da apresentação (da verdadeira apresentação) temos uma relação com algo 'correspondente'» (Husserl, 1980: 475).

Para concluir as suas reflexões sobre os «modos de reprodução, fantasia, consciência de imagem» (textos $n^{\circ} 15$ e 16) Husserl observa de forma concisa:

Temos de generalizar o conceito de fantasia (digamos presentificação). Há duas formas fundamentais de presentificação: 1) a reprodutiva, 2) a perceptiva, isto é, a presentificação em imagem, numa apresentação imagética. (...) Tem de se separar estas modificações daquelas que transformam a posição numa não-posição. (Cruzamento das duas espécies de distinções.) Para além disso, não se podem confundir percepções não posicionais com vivências que apresentam por imagem: ou seja, com presentificações. (Husserl, 1980: 475s.; itálicos parcialmente meus)

Estas incursões a respeito da consciência de imagem no percurso intelectual de Husserl posterior às lições de 1904/05 devem ter deixado claro que, como se pode observar nos textos mais tardios, a sua confiança do tempo das lições de que, graças às suas análises, a «representação de imagem» teria sido «tornada totalmente clara», teve de dar lugar, ao longo de muitas modificações no que fora anteriormente assumido, a muitas novas distinções naquilo que inicialmente era tomado como simples.

Com especial referência à apresentação estético-artística em imagem, chama-se brevemente a atenção para uma modificação no pensamento de 
Husserl, que pela sua parte deixa, de novo, questões em aberto, tais como a de saber de que forma as respectivas relações constitutivas da consciência poderiam ser explicitadas de modo mais detalhado. No caso da arte, Husserl põe em causa a sua doutrina geral da consciência de imagem como imageticidade. No texto $\mathrm{n}^{\mathrm{o}} 18 \mathrm{~b}$, que tem aproximadamente origem no ano de 1918 (Husserl, 1980: 514ss.), Husserl escreve em jeito de autocrítica:

Não pode ser dito que a arte se deva mover necessariamente na esfera da intuitividade. Anteriormente pensei que pertencia à essência da arte apresentar em imagem e entendi este apresentar como um figurar. Contudo, vendo melhor, isso não está correcto. (Husserl, 1980: 514)

De facto, nas lições de 1904/05, no contexto de uma discussão da «contemplação estética» de uma imagem, está escrito que «a intenção que vai para além do objecto-imagem (...), dirigida a uma intuição mais rica» pode aqui «recuar», porque «o visar não diz exclusivamente respeito ao tema, havendo antes um interesse, e na verdade um interesse estético emotivo [ein ästetisches Gefühlsinteresse] no objecto-imagem» (Husserl, 1980: 52; $c f$. também Husserl, 1980: 36s.). ${ }^{9}$ Contudo, diz-se a seguir, a «consciência do tema da imagem está aqui também presente e não é de todo insignificante, pois sem ela não há imagem estética (...)»(Husserl, 1980: 52, itálicos parcialmente

\footnotetext{
${ }^{9}$ Num texto presumivelmente originado no tempo das lições, reproduzido no volume XXIII como anexo IX (Husserl, 1980: 149 ss.), encontram-se mais considerações dignas de nota sobre a consciência estética de imagem. Pode ter particular interesse o facto de aí Husserl dar já voz, a respeito da questão da figuratividade da imagem artística, a uma consciência clara da especificidade deste tipo de apresentação imagética. Já nessa altura, Husserl pergunta, à luz do exemplo de uma pintura de Ticiano, «é a obra de Ticiano um ser-figura, e através da figuração um tornar manifesto? ... é o 'tema' ['Sujet'] um objecto [Gegenstand] representado através da imagem como figura e que deve servir como fundamento a uma representação inautêntica a seu respeito? Dá uma outra intuição uma representação mais própria do que é visado na consciência de imagem estética? Será que eu teria uma representação mais própria se representasse o objecto [Objekt] como objecto [Gegenstand] ele próprio e de todos os lados? [...] Do objecto, sim, mas isso não seria um preenchimento de uma intenção imagética. $\mathrm{O}$ interesse dirige-se aqui [...] ao apresenta-se do objecto no objecto-imagem. [...] $\mathrm{O}$ que me interessa nisso está aí, não é representado indirectamente» (p. 154s.).
} 
meus). Em contrapartida, no texto de 1918, Husserl tenta argumentar pormenorizadamente a favor do ponto de vista de que a arte «é o reino da fantasia enformada, perceptiva [perzeptiver] ou reprodutiva, intuitiva, mas em parte também não intuitiva», e no curso destas reflexões põe radicalmente em causa o papel da figuratividade.

O que salta à vista é que Husserl não o faz através do exemplo de imagens comuns, físicas (pinturas, desenhos, etc.), mas antes por meio da análise da peça de teatro [Schauspiel]. Ele escreve:

Numa representação teatral, vivemos num mundo de fantasia perceptiva [perzeptiver Phantasie], temos "imagen" na unidade coerente de uma imagem, mas nem por isso figuras ${ }^{10}$. Se Wallenstein ou Ricardo III é representado [dargestellt $]$ no palco, trata-se certamente de apresentações figurativas, se bem que deve ser considerada a questão até que ponto esta figuratividade tem uma função estética. Em primeiro lugar, não tem seguramente figuratividade, mas antes imageticidade no sentido de fantasia perceptiva [im Sinn der perzeptiver Phantasie] como imaginação imediata. (...) Os actores criam uma imagem, a imagem de um acontecimento trágico, cada um deles [cria] a imagem de uma personagem a agir, etc. Mas " $a$ imagem de" não significa aqui a figura de. [...] A representação [Darstellung] do actor também não é uma apresentação [Darstellung] no sentido em que dizemos de um objecto-imagem que se apresenta nele o tema da imagem. (...) Nem o actor nem a imagem, que para nós é a sua obra (...), é um objecto-imagem no qual se figura um outro objecto, um tema da imagem, real ou até ficcional. Há um figurar real num retrato (...). E aqui a figuratividade pode, de resto, pertencer à consciência estética como tal. Onde é representada uma peça de teatro, não é necessário ser estimulada a consciência de figuração e o que aparece nela é um fictum perceptivo puro.

${ }^{10}$ N.d.T.: Optou-se por traduzir Abbild por «figura» e respectivos cognatos. Esta tradução permite não só manter a relação entre todos os termos derivados de Abbild (figura), abbilden (figurar), Abbildung (figuração), Abbildlichkeit (figuratividade), etc., como remete também para a noção de figuração no mesmo sentido em que se fala, por exemplo, de «pintura figurativa». No entanto, o leitor deve ter em mente, em passos em que Husserl usa a noção de $A b b i l d$ (figura), que esta palavra significa também «imagem copiada» ou «imagem decalcada». Assim, por exemplo, quando Husserl diz que a imagem não é necessariamente uma «figura», Husserl quer dizer que a imagem não é necessariamente uma cópia ou decalque de um original. 
Vivemos na neutralidade, (...) tudo o que acontece aí [...] tem o carácter do como-se. [...] Em nenhum lugar, no entanto, emerge aqui a apresentação no sentido de figuração, a consciência na qual um fictum perceptivo torna consciente, "visa", figurando, um outro objecto, seja este real ou mesmo ficcional. (Husserl, 1980: 514ss., itálicos parcialmente meus)

Alguma forma de apresentação está, no entanto, em jogo. Husserl prossegue por meio de aspas do modo que se segue: «os seres humanos de carne e osso, os actores, as coisas reais chamadas cenários, os móveis reais, os cortinados, etc., 'apresentam', servem para nos colocar na ilusão artística», e pergunta: «o que caracteriza então esta 'apresentação'?», na qual, como explica logo a seguir, não estamos perante uma «ilusão no sentido comum, uma 'aparência' a que 'sucumbimos'» (Husserl, 1980: 516, itálicos meus). A sua resposta é:

No caso da representação teatral, o drama, este excerto de um mundo de aparência, aparece, mas não começamos aí com uma percepção normal. Não começamos com a tese de realidade do que aparece perceptivamente [perzeptiv]. [...] Portanto não [é] como na ilusão, onde nos colocamos no terreno da experiência. [...] Antes [...] temos desde o princípio apenas a "imagem" artística e a coisa real que desempenha a função de apresentação; aquilo que é experienciado de forma não modificada está constantemente encoberto. De forma encoberta, há, no entanto, consciência dela, apenas de modo não intuitivo e daquela maneira peculiar a que aqui a palavra encobrimento alude. Deste modo, pomo-nos desde o início no terreno da "ilusão", da "aparência”, que para nós é caracterizado, noutro sítio, (...) como aparência "estética". Por outras palavras, pomo-nos no terreno da intuição da fantasia. (Husserl, 1980: 516s., parte dos itálicos meus)

A pergunta que se impõe a respeito destas reflexões de Husserl sobre a peça de teatro como «uma fantasia puramente perceptiva [rein perzeptive Phantasie]» na atitude de neutralidade (Husserl, 1980: 518 e passim), sobre o seu alcance relativamente à sua teoria da consciência de imagem e do ser-imagem necessitaria certamente de uma discussão mais prolongada; de todo o modo, é difícil contornar a formulação inicial de Husserl nas lições de 1904/05: «se juntamente com a imagem não é dada a relação consciente com qualquer coisa figurada, não temos imagem nenhuma» (Husserl, 1980: 31) e as suas 
observações no texto $\mathrm{n}^{\circ} 16$ de 1912: «a apresentação pertence à essência da consciência de imagem; a consciência de imagem não é simplesmente consciência perceptiva [perzeptives Bewusstsein] e quando muito uma consciência perceptiva [perzeptives Bewusstsein] que ainda se encontraria entretecida com uma [consciência] reprodutiva (a saber, uma consciência de fantasia)» (Husserl, 1980: 471), assim como a «apresentação tem uma comunidade essencial com a reprodução: a saber que em toda a componente da apresentação (da verdadeira apresentação) temos uma relação com algo 'correspondente'» (Husserl, 1980: 475).

\section{O estatuto das sensações, dos fantasmas e a rejeição do «esquema- conteúdo-apreensão»}

Em terceiro lugar, para finalizar, depois das lições de 1904/05, o que já tinha sido descoberto a respeito das sensações e fantasmas como conteúdos das apreensões da percepção, da fantasia ou da recordação, apareceu a «uma nova luz» a Husserl a partir do momento em que começou a aprofundar a determinação da relação entre a percepção e a fantasia assim como a essência das presentificações intuitivas em geral através da análise da consciência do tempo (Husserl, 1980: 92). ${ }^{11}$ Precisamente a propósito do «esquema-conteúdoapreensão» (sensações - fantasmas e as apreensões que the são correspondentes), que fora central para a sua determinação da relação entre presentação e presentificação, resultaram grandes dificuldades que conduziram a novas descobertas. O mais tardar cerca de 1905/06, Husserl começou a ficar insatisfeito com a sua tese defendida até aí de que os fantasmas são conteúdos, «que aparecem como presentes», mas que devem sofrer a apreensão ou a «apercepção no sentido de qualquer coisa que não se encontra ela própria aí» ${ }^{12}$.

\footnotetext{
${ }^{11}$ Este importante domínio de problemas é aqui apenas tratado de forma breve, porque ele adquire importância de uma forma muito mais abrangente no contexto da análise husserliana da consciência do tempo. Sobre isto ver os textos respectivos e a introdução detalhada de Rudolf Bernet na Studienausgabe dos Texte zur Phänomenologie des inneren Zeitbewusstseins (1893-1917) (Husserl, 1985).

${ }^{12} C f$. em particular no volume XXIII, $\mathrm{n}^{\mathrm{o}} 1$ (Husserl, 1980: 107), ${ }^{\circ} 1$ e 2, Ergänzungen de cerca de 1905/06; além disso Beilage XIII (Husserl, 1980: 166ss.), Beilage XII
} 
O retorno à consciência original do tempo ensinou-o a compreender que as «sensações» e «fantasmas» não são simplesmente objectos, por assim dizer, acabados, «uma espécie de coisinhas», como escreve nas Ideen (1913, § 112), a partir das quais, na qualidade de «conteúdos» ou «'elementos' psíquicos», se constrói a vida consciente. Os chamados conteúdos da apreensão são já doações conformes à consciência, tal como ele expõe novamente nas Ideen I (1913, 112), uma «diferença de consciência», de acordo com a qual «o fantasma não é um mero dado sensível anémico, mas antes, de acordo com a sua essência, a fantasia $d o$ dado sensível correspondente», sendo que é necessário ter em conta que «que este 'de' não pode ocorrer através da diluição, por substancial que ela seja, da intensidade, da plenitude [Inhaltsfülle], etc., do respectivo dado sensível».

Em particular a análise do fenómeno da retrotracção temporal original, desde as «lições sobre o tempo» de 1905, parece ter chamado a atenção de Husserl para as fraquezas da sua «teoria da representação [Repräsentationstheorie] que operava com 'conteúdos' vividos (por exemplo, conteúdos sensíveis) e, em conformidade com isso, considerava-os como apreendidos desta ou daquela maneira» ${ }^{13}$. Já alguns anos antes das Ideen de 1913, onde Husserl acentua que se trata de uma diferença de consciência, esta revisão significativa do seu «esquema-conteúdo-apreensão» é expressa claramente no texto $\mathrm{n}^{\mathrm{o}} 8$, que pode ser datado aproximadamente do Inverno de 1909 (pp. 265ss.). Husserl pergunta: «qual é fonte das tentativas novamente repetidas e sempre de novo falhadas de esclarecer a relação entre percepção e fantasia ou antes a fonte do falhanço destas tentativas?» A sua resposta é:

Eu penso o seguinte! Não percebi (e ninguém percebeu em geral) que por, exemplo, a fantasia de uma cor não é algo presente; que não é dada a vivência "cor" que, nesse caso, representaria [repräsentiert $]$ a cor verdadeira. De acordo com isto, a cor-sensação e a cor-fantasma, em si mesmas, seriam a mesma coisa, apenas dotadas de uma função diferente. Eu tinha o esquema

(Husserl, 1980: 163ss.) e Beilage XVI (Husserl, 1980: 202ss.), todos aproximadamente de 1904/05.

13 Cf. na Studienausgabe, Texte zur Phänomenologie des inneren Zeitbewusstseins (1893-1917), Nr. 48 (Husserl, 1985: p. 184s.), e os números seguintes, assim como a introdução de Bernet, (Husserl, 1985: XLVss.) 
“conteúdo da apreensão e apreensão" - e ele tinha certamente sentido. Contudo, antes de mais, no caso da percepção como vivência concreta, não temos uma cor como conteúdo da apreensão e depois um carácter de apreensão, que produz a aparição. E de igual modo não temos, no caso da fantasia, de novo, uma cor como conteúdo da apreensão e depois uma apreensão modificada, aquela que produz a aparição da fantasia. Antes: $a$ "consciência" consiste, de ponta a ponta, em consciência e a sensação tal como o fantasma são já "consciência". Aí temos, a princípio, a percepção como consciência impressional (originária) do presente, consciência do que está aí [Selbstda-Bewusstsein] e afins, e a fantasia (...), como consciência do presente, modificada reprodutivamente, consciência daquilo que está como que presente, da fantasia do presente (Husserl, 1980: 265s.)

Esta revisão claramente inovadora do esquema-conteúdo-apreensão empiristasensualista a favor da compreensão do facto de que a consciência é constituída de ponta a ponta por consciência pode ser considerada como fundamental para a teoria fenomenológica de Husserl da consciência. ${ }^{14}$ Num texto originado aproximadamente em 1918, que pertence aos Bernauer Manuskripten über das Zeitbewusstsein («Manuscritos de Bernau sobre a consciência do tempo»), Husserl exprime de forma muito clara e autocrítica o que havia desenvolvido a esse propósito, de forma gradual, uma década antes:

No sentido mais estrito, o apreender é, porém, uma consciência originalmente doadora, perceptiva (...). Manifestamente não é, em si mesma (segundo a sua própria essência intencional), uma consciência que modifica, [e] a respeito do que é modificado por ela [seines Modifikates], uma [consciência] apreensiva (...) Era falso considerar a fantasia como um apreender particular cujos conteúdos de apreensão seriam os "fantasmas". A fantasia é uma modificação da percepção correspondente, os conteúdos da fantasia são modificações [Modifikate] dos dados sensíveis correspondentes, eles próprios não são dados sensíveis que seriam apenas apreendidos de outro modo. (...) Tal como uma casa fantasiada, passada ou futura, não é uma casa

${ }^{14} C f$. também, por exemplo, Husserl (1950: $\$ 86$ e $\$ 112$ ), onde Husserl nomeia, entre outras coisas, a falta de «exercício na análise fenomenológica autêntica», precisamente em referência à falta de compreensão de que na sensação e no fantasma se trata de uma «diferença de consciência»! 
(uma realidade presente), o fantasiar, o recordar, o esperar [Erwarten] não são apreender, mas antes uma modificação sua. (Husserl, 2001: 175ss.; itálicos meus)

Em seguida, segue-se ainda a frase, a que já se fez referência acima e que conclui de forma apropriada a apresentação dos três domínios de problemas que apareceram no início da terceira parte das lições de 1904/05 (nº 1):

Esta intencionalidade extremamente peculiar das “modificações” já apareceu nas Ideen (ela já tinha sido utilizada, uma série de anos antes em lições, de uma forma minuciosa para o esclarecimento de diferentes tipos fundamentais de modificação assim como de todos os tipos de "presentificação"). (Husserl, 1980: 176; itálicos meus)

\section{Bibliography}

AldEA, A. S. (2013). «Husserl's Struggle with Mental Images: Imaging and Imagining Reconsidered». Continental Philosophy Review, 46 (3): 371-394. $<10.1007 / \mathrm{s} 11007-013-9268-7>$

Brentano, F. (1959). Grundzüge der Ästhetik. Bern: A. Francke.

FERENCZ-Flatz, C. (2009). «Gibt es perzeptive Phantasie?: Als-obBewusstsein, Widerstreit und Neutralität in Husserls Aufzeichnungen zur Bildbetrachtung». Husserl Studies, 25 (3): 235-253. <10.1007/s10743-0099062-X>

HUSSERL, E. (2009). Untersuchungen zur Urteilstheorie. Texte aus dem Nachlass (1893-1918). Husserliana 40, ed. Robin D. Rollinger. Dordrecht: Springer.

- (2004). Wahrnehmung und Aufmerksamkeit. Texte aus dem Nachlass (18931912). Husserliana 38, ed. Thomas Vongehr und Regula Giuliani. Dordrecht: Springer.

- (2001). Die Bernauer Manuskripte über das Zeitbewusstsein (1917/18). Husserliana 33, ed. Rudolf Bernet e Dieter Lohmar. Dordrecht: Kluwer.

- (1985). Texte zur Phänomenologie des inneren Zeitbewusstseins (18931917), ed. Rudolf Bernet. Hamburg: Meiner.

- (1984). Logische Untersuchungen, vol. 2. Husserliana 19/1, ed. Ursula Panzer. Den Haag: Martinus Nijhoff. 
- (1980). Phantasie, Bildbewusstsein, Erinnerung. Zur Phänomenologie der anschaulichen Vergegenwärtigungen, Texte aus dem Nachlass (18981925). Husserliana 23, ed. Eduard Marbach. Den Haag: Martinus Nijhoff.

- (1966). Zur Phänomenologie des inneren Zeitbewusstseins. Husserliana 10, ed. Rudolf Boehm. Den Haag: Martinus Nijhoff.

- (1959). Erste Philosophie (1923/24), Zweiter Teil. Husserliana 8, ed. Rudolf Boehm. Den Haag: Martinus Nijhoff.

- (1950). Ideen zur einer reinen Phänomenologie und phänomenologischen Philosophie, Husserliana 3, ed. Walter Biemel. Den Haag: Martinus Nijhoff.

KLEIST, H. vON (1970). Sämtliche Werke und Briefe, Zweiter Band. Darmstadt: Wissenschaftliche Buchgesellschaft.

REIKO, I. (2011). «Husserls Begriff des Bildes. Zu einer genetischen Phänomenologie des Bildbewusstseins». In: Yoshihiro Nitta, Toru Tani (eds.), Aufnahme und Antwort. Phänomenologie in Japan I. Würzburg: Königshausen \& Neumann, 175-199.

RozzonI, C. (2016). "Cinema Consciousness: Elements of a Husserlian Approach to Film Image», Studia Phaenomenologica, 16, Special Issue: "Film and Phenomenology", ed. by C. Ferencz-Flatz and J. Hanich, 295324

SHuM, P. (2015). «The Evolution and Implications of Husserl's Account of the Imagination.» Husserl Studies, 31 (3): 213-236. <10.1007/s10743-0159175-3>

EDUARD MARBACH is a retired Professor of Philosophy in the Institut für Philosophie at the University of Bern. Before being appointed as Professor at the University of Bern, he had worked at the Husserl-Archives in Leuven and lectured at the University of Leuven. He has also been a collaborator at Jean Piaget's Centre Internationale d'Epistémologie Génétique in Geneva and a Visiting Scholar at several universities, including Oxford, Berkeley and New York. He is the editor of Husserliana XXIII, Phantasie, Bildbewusstsein und Erinnerung. Zur Phänomenologie der anschaulichen Vergegenwärtigungen and the author of several books and research papers on Husserlian phenomenology and phenomenological philosophy of mind, such as Das Problem des Ich in der 
Phänomenologie Husserls (Springer, 1974), An Introduction to Husserlian Phenomenology (co-authored with Rudolf Bernet and Iso Kern, Northwestern University Press, 1993), and Mental Representation and Consciousness: Towards a Phenomenological Theory of Representation and Reference (Kluwer, 1993). 